\title{
GESTÃO AMBIENTAL EM RODOVIA: PERÍCIA EM RODOVIA PARA IDENTIFICAR E VALORAR IMPACTO AMBIENTAL POR DESCARTE E ACÚMULO DE RESÍDUOS SÓLIDOS
}

\section{ENVIRONMENTAL MANAGEMENT IN HIGHWAY: HIGHWAY EXPERTISE TO IDENTIFY AND ASSESS ENVIRONMENTAL IMPACT FOR DISPOSAL AND SOLID WASTE ACCUMULATION}

\author{
Dennis Pinto de Menezes \\ Pós-graduação em Ciências Ambientais /UFRJ \\ Carlos de Azevedo \\ Pós-graduação em Ciências Ambientais /UFRJ \\ Elenice Rachid da Silva \\ Programa de Engenharia de Transportes da Coppe/UFRJ \\ Andréia Lisboa da Cunha \\ Sócia ETHLC (Escritório Tec. H.Lisboa da Cunha) \\ Gustavo Aveiro Lins \\ Pesquisador OUERJ/UN-HABITAT - RJ - Brasil \\ Josimar Ribeiro de Almeida \\ Universidade do Estado do Rio de Janeiro - UERJ \\ Universidade de São Paulo - USP
}

\section{RESUMO}

Este artigo buscou avaliar o Sistema de Gestão Ambiental da Concessionária da BR-116 baseado nas informações obtidas na execução do levantamento e da valoração do passivo ambiental, escopo de uma perícia demandada por uma Ação Civil decorrente dos impactos ambientais por lançamentos e acumulo de resíduos sólidos na Rodovia Rio-Teresópolis/BR 116. A perícia foi executada durante os meses de Fevereiro a Abril de 2001, abrangendo uma área com cerca de 22,0 ha, em um segmento de 14,40 km (do $\mathrm{km} \mathrm{104,0} \mathrm{até} \mathrm{o} \mathrm{km} \mathrm{896,0),} \mathrm{a} \mathrm{jusante} \mathrm{e/ou} \mathrm{a} \mathrm{montante} \mathrm{adentrando} \mathrm{até} 15$ (quinze) metros nas bordas florestais (área de amortecimento) do Parque Nacional da Serra dos Órgãos, doravante denominado PARNASO.

Palavras-chave: Gestão ambiental em rodovia, valoração do passivo ambiental, resíduos sólidos em rodovia. 


\section{ABSTRACT}

This paper aimed to evaluate the Environmental Management System of the Concessionaire of the BR-116 highway, based on information obtained from a survey and evaluation of environmental liabilities, carried out as the scope of work for the defendant's expert witness in a civil action arising from the environmental impacts of releases and accumulation of solid waste along the Rio-Teresópolis/BR 116. The expert's survey was performed during the months of February to April of 2001, covering an area of about 22.0 ha, in a segment of $14.40 \mathrm{~km}$ (from km 104.0 to $\mathrm{km} 896$ ), downstream and/or upstream by entering fifteen (15) meters into the forest edges (buffer zone) of the National Park of the Organ Mountains, hereinafter PARNASO

Keywords: Environmental management in highway, valuation of environmental liabilities, waste in highway.

\section{INTRODUÇÃO}

O crescimento populacional da humanidade, os avanços tecnológicos e a consequente intensificação da exploração dos recursos naturais, vêm causando sérios danos ao meio ambiente, evidenciando a insustentabilidade dos modelos políticos, econômicos e sociais adotados, intensificando o êxodo rural e o inchamento das grandes cidades vinculado à criação de megaestruturas, como por exemplo, plantations, conturbações, arranha-céus, imensos parques industriais, portos, aeroportos, ferrovias, etc.

A construção de rodovias tem como objetivo servir como via de transporte terrestre para pessoas e cargas. É impossível imaginar o mundo de hoje sem autoestradas, pois por meio delas são transportadas as safras agrícolas e os insumos necessários para produzi-las, os produtos industriais e as matérias primas para elaborá-los, quase toda a produção intelectual humana impressa, notícias em jornais e revistas, máquinas, combustíveis, produtos minerais e toda espécie de material que se possa imaginar que a humanidade utilize; além disso, são as principais vias de transporte de pessoas em curta e média distância.

Entretanto, estas representam um dos maiores males da civilização quanto aos impactos sobre o ambiente natural acarretando degradação ao meio físico, biótico e, ao próprio meio antrópico, o que tomou imperativo o estabelecimento de normas para que se disciplinassem as atividades humanas 
nesta atividade, protegendo juridicamente a natureza através de sanções impostas de forma coercitiva pelo Estado.

Dentro do aspecto legal, as rodovias devem ser objeto de EIA-RIMA sempre que possuírem duas ou mais faixas de rolamento, onde se enquadram todas as Rodovias Federais, a maioria das Estaduais e algumas Municipais. A legislação e as normas técnicas referentes às rodovias estão enumeradas na bibliografia.

A avaliação de impacto ambiental das rodovias deve incluir todas as fases, mas no Brasil ainda é inexistente na fase de operação, sendo pouco ou nada exigido pela legislação nesta fase, embora talvez crie mais impactos do que as demais, pois tem um prazo de duração indefinido, podendo chegar a séculos.

Este trabalho foi elaborado baseado no laudo e nos aspectos da execução de uma perícia solicitada por uma das partes (a ré) que explora por concessão a operacionalização da rodovia BR 116, esta, possuindo um segmento inserido em uma Unidade de Conservação de Proteção Integral e Permanente (Parque Nacional da Serra dos órgãos PARNASO), no município de Guapimirim-RJ.

O estudo de caso realizado procurou verificar as condições de regularidade e legalidade ante a degradação do meio ambiente provocada por resíduos sólidos e à devida valoração e reparação dos possíveis danos ambientais decorrentes dos mesmos.

Objetivou também levantar os pormenores dos aspectos que concorreram para tal, e a partir dessas particularidades, do diagnóstico e da avaliação ambiental, propor mecanismos para o gerenciamento integrado de resíduos sólidos na rodovia, possibilitando consenso ao uso sustentável da via, uma infraestrutura supra regional de relevante importância nacional, com a existência do Parque.

Localizado nos municípios de Petrópolis, Teresópolis, Magé e Guapimirim, no Estado do Rio de Janeiro, com coordenadas Latitude: $22^{\circ} 24^{\prime}$ -

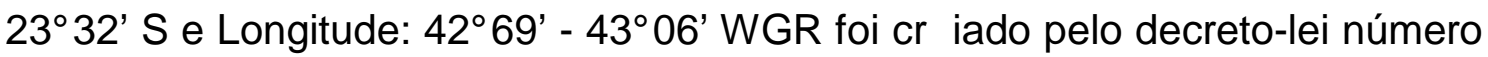
1822 de 10 de novembro de 1939, tendo seus limites definidos apenas em 2 de agosto de 1984, graças ao decreto número 90.023 - a criação de um Parque 
não pressupunha a definição de seus limites, o que deve explicar o lapso de 45 anos entre os dois decretos, Sua finalidade inicial, além do abastecimento de águas de Teresópolis, inclua os estudos botânicos, faunísticos e ecológicos decorrentes de sua exuberante vegetação.

A Mata Atlântica, os monumentos geológicos e de modo geral o relevo peculiar àquele trecho da Serra do Mar, bem como as cachoeiras e os rios reafirmam nos dias de hoje seu potencial turístico. A rodovia está, portanto inserida em um contexto em que se por um lado traz o progresso, por outro, se não corretamente administrada poderá levar a degradação do meio que a circunda.

A geomorfologia do PARNASO é dominada por picos, paredões e encostas de gnaisse e granitos datados da era pré-cambriana tardia, o Parque Nacional situasse numa área da era primitiva (Proteozóica), cuja unidade geológica denominasse de Suíte Intrusiva Serra dos Órgãos, apresentando uma litologia granítica pós - tectônico, em geral cinza claro e de grã media fina granitos e granodiorítos sistectônicos, grosseiros, e em parte recristalizados e com domínios restritos magmáticos e nações para tipos facodais, Desta forma, está localizado numa das principais falhas geológicas registradas em território brasileiro. Granitos do Laurentiano são também comuns na área do parque.

Em virtude da sua localização na região mais alta do estado, as temperaturas no parque são sensivelmente inferiores à média fluminense. No inverno, os termômetros podem atingir a mínima de $-5^{\circ} \mathrm{C}$ ou ainda menos, enquanto que a média é de $11^{\circ} \mathrm{C}$. No verão, a temper atura média é de $24^{\circ} \mathrm{C}$. Nessas condições, são frequentes a névoa com chuvas persistentes, devido ao bloqueio pela serra das massas de ar oceânicas. A partir da cota de $800 \mathrm{~m}$, é constante o elevado índice de umidade relativa do ar em tomo de $84 \%$ e os níveis pluviométricos assinalam uma média de $1.700,0 \mathrm{~mm}$ de chuva.

No que diz respeito ao estudo, a área periciada compreende um trecho de 300 a 800 metros de altitude correspondendo as Regiões Fitoecológicas denominadas "Floresta Ombrófila densa montanha e sub-montanha".

A concessão da administração da Rodovia BR-116/RJ, estendesse do trecho compreendido entre a divisa do município de Além Paraíba ( $\mathrm{km} \mathrm{2)}$, até o entroncamento da BR-040- Rodovia Washington Luís (km 144,50), 
compreendendo a operação e manutenção da autoestrada, sendo que a manutenção é terceirizada pela Empresa Airless S.A.

Com impressionantes números de 30 toneladas por mês é que a concessionários Caminhos do Paraná, que administra $405 \mathrm{~km}$ de rodovias, quantifica o lixo retirado das pistas de rolamento. Diariamente a equipe de Inspeção do Tráfego, retira objetos jogados pelos usuários que esbanjam desrespeito ao meio ambiente e à própria segurança e a de seus semelhantes.

A poluição gerada pelo lixo modifica o meio ambiente, altera seus processos naturais e causa impactos devastadores como, por exemplo, grandes enchentes por entupimento de bueiros, assoreamento de rios, transmissão de doenças, degradação do solo e muitos outros.

A Caminhos do Paraná ciente desse aspecto ambiental, implementou o Programa Caminhos Limpos que trata justamente do gerenciamento dos resíduos produzidos pela empresa e lança, nesta sexta-feira, dia 19 de setembro, campanha para combate a esse mal. A empresa, que é certificada na norma ISSO 14001, investiu cerca de $\mathrm{R} \$ 7$ mil em material educativo e pretende atingir usuários e comunidades que vivem ou mantêm negócios às margens da rodovia.

\section{METODOLOGIA}

O modelo adotado para a avaliação ambiental não enfoca em detalhes o impactos positivos decorrentes da existência da infraestrutura, uma vez que os benefícios são extensivos a todos os segmentos que dela se servem, favorecendo a população e a economia local e regional, tanto pela preservação do investimento feito na construção da via, como nas questões de segurança de transito, diminuição dos custos e tempo de transporte, conforto e segurança do usuário e comunidades adjacentes, dentre outras benfeitorias.

Nesse sentido, a avaliação ambiental se ateve às potenciais repercussões ambientais negativas e, via de regra, temporárias, visando estabelecer as correções a serem empregadas no ajustamento às não conformidades, orientando o controle ambiental a ser efetivado na execução de 
eventuais obras e na operacionalidade da via segundo a natureza das intervenções e nas áreas de maior fragilidade.

A correlação entre as intervenções previstas e os condicionantes ambientais e legais das áreas de inserção da via possibilitou atribuir dois níveis de complexidade ambiental referentes ao objeto do estudo, correspondendo um deles às maiores potencialidades de impactos (Análise de impacto ambiental e Análise de risco ambiental) e restrições legais e o outro, às interferências que, de modo geral serão extensivas a toda a infraestrutura, como por exemplo, o próprio tráfego.

No estabelecimento do grau de complexidade, definição e hierarquização dos níveis de impacto foram considerados os aspectos destacadamente mais relevantes a serem enfrentados, particularmente nas etapas de fiscalização, monitoramento e controle operacional rotineiro da via e na execução de obras, tomando-se por critério que o nível mais alto de impactos agrega, ainda, os impactos presentes no nível inferior, que potencializam o passivo herdado da administração anterior.

Foi considerado de maior criticidade quanto aos aspectos ambientais analisados no estudo, o fato da rodovia Percorrer terreno com condicionantes legais e ambientais mais restritivos, expressos fundamentalmente nas interferências com:

- $\quad$ área legalmente protegida: Unidade de conservação de proteção integral e permanente (Parque Nacional) que apresenta grandes restrições a intervenções:

- áreas de proteção de mananciais com captações superficiais de água para abastecimento urbano a jusante da rodovia;

- áreas com características geológicas, pedológicas e climáticas que por si só apresentam riscos quanto a deslizamentos, escorregamentos outros fenômenos naturais, que podem ser deflagrados ou potencializados por ações antrópicas.

A metodologia adotada observou critérios de coleta, análise e classificação dos detritos que compuseram as amostras e as possíveis fontes geradoras dos descartes no segmento do eixo viário estudado, com extensão de 14,4 km - do km 104 (ponte sobre o Rio Bananal) até o km 89.6 (Alto do 
Soberbo) -, abrangendo uma área de 21,6 ha, localizando-se no Município de Guapimirim.

Por se tratar de trabalho que envolvia riscos à saúde, adotou-se medidas de segurança apropriadas, adaptando os procedimentos, que se desenvolveriam em condições adversas e atípicas, permitindo desempenho e eficácia ao trabalho, levando-se em conta: as NR's - normas reguladoras do MT; as normas padrão na coleta e análise dos resíduos (ABNT - NBR), as NR's do DNER e principalmente a Legislação Ambiental Federal e Estadual pertinente em todas as etapas do estudo.

O levantamento dos resíduos sólidos foi executado mediante procedimentos adaptados, observando-se particularidades que diferem de uma abordagem comum, ou seja, diferentes das adotadas em locais urbanos, industriais ou mistos, visto se tratar de uma rodovia que corta um trecho escarpado da Serra dos Órgãos. Assim sendo, foram feitos estudos, desde a geração dos resíduos aos impactos ambientais, com suas possíveis consequências, sistematizando as informações tendo como resultando a síntese de um sistema de gerenciamento de extrema importância para a operação da rodovia e o meio ambiente.

Os resíduos sólidos foram coletados nas margens da rodovia e bordas do parque, armazenados em depósito, forrados e cobertos por lonas plásticas, etiquetados por local e data, sendo posteriormente separados, classificados e pesados, dentro dos aspectos predeterminados. Foi procedida a tomada de imagens fotográficas, dos locais de coleta, do depósito e dos processos, anotando-se os resultados (numéricos e qualitativos) para que em seguida se comentasse sobre cada amostra e com esses dados fosse respondido cada quesito formulado, elaborando um parecer segundo a especificidade e qualidade dos materiais encontrados (origem, classes, características e propriedades físico-químicas).

Foram determinados além do tipo e quantidade de resíduos, os locais de maior incidência de disposição, tanto na faixa de domínio quanto na área de influência direta da rodovia (zona de amortecimento), sendo esta considerada como a dimensão alcançada pelos resíduos arremessados, e ou simplesmente deixados e ou descarregados por usuários da mesma, e/ou deslocados pela 
gravidade, arrastados por ventos e/ou pelas enxurradas advindas das precipitações pluviométricas comuns na região como também transportados através do sistema de drenagem, tanto a montante como a jusante da via, para o interior da floresta até cerca de quinze metros.

Embora na práxis pericial e na elaboração de seu respectivo laudo, sejam preceituadas abordagens esclarecedoras, objetivas e sucintas, neste trabalho estas características não são seguidas à risca, por se tratar de um estudo de caso académico, onde informações adicionais são necessárias para uma perfeita demonstração e entendimento dos vieses inerentes ao tema.

Os procedimentos de coleta, amostragem e análise do material foram realizados de acordo com as normas ABNT - NBR, observando-se os que influíram nos fatores, geração e dinâmica dos resíduos, assim como: o fluxo de veículos e a composição do tráfego, a sazonalidade e hábitos culturais, além dos aspectos fisiográficos como: a urbanização, o clima, o relevo, os recursos hídricos e classes de solos predominantes.

A limpeza e manutenção da rodovia são organizadas em uma matriz de procedimentos adotada por uma empresa terceirizada, sendo que a coleta para amostragem foi adaptada em função desta matriz, procurando-se obter representatividade amostral, considerando-se os fatores descritos acima, correlacionando-os com as fontes geradoras dos descartes e a tipologia dos resíduos coletados na rodovia e no interior da borda florestal.

A amostragem foi então executada em pontos e segmentos definidos conforme a quantidade e frequência de ocorrência, bem como nos locais de notório descarte com reincidência, a exemplo dos casos do km 91,0; 97,0 e 98,0 .

O recolhimento dos resíduos na pista, nas suas margens e nas valetas de drenagem foi realizado por um homem as segundas, quartas e sextas, no trecho da serra do $\mathrm{km} \mathrm{104,0} \mathrm{ao} \mathrm{km} \mathrm{89,6,} \mathrm{sendo} \mathrm{este} \mathrm{procedimento} \mathrm{rotineiro} \mathrm{e}$ sequencial. Na área do Parque, a coleta foi conduzida por seis homens que adentravam na mata e nos grotões com o auxílio de cordas.

Destacamos que este segundo procedimento, conforme informação dos trabalhadores, foi adotado após a intervenção da administração do parque através do órgão ambiental competente. 
As amostras eram cobertas à noite e em dias chuvosos, em suas interfaces, por lonas plásticas para sua proteção e descobertas a dia para exposição ao sol, evitando assim descaracterização das mesmas, principalmente quanto ao teor de umidade, o que influenciaria no peso das mesmas.

O material era então separado por suas características físicas matéria orgânica, papel, papelão, material ferroso e não ferroso, vidros, cerâmicas, louças, madeiras, borrachas, panos e trapos e diversos plásticos especificados abaixo em razão de sua predominância no total amostral.

Executada a triagem se procedeu à pesagem de cada componente, tabulando-se dados obtidos para cada amostra.

A partir das análises amostras, foram apontadas as contribuições das classes e grupos de resíduos encontrados na rodovia e na área do parque.

As amostragens para a análise de umidade (U\%) e de parâmetros físicoquímicos (densidade) não foram realizadas, pois fogem ao objetivo do trabalho.

O quadro 1 aborda a sequência do procedimento padrão adotado para a coleta das amostras objetivando a análise de composição gravimétrica.

Quadro 1: Procedimentos de coleta e amostragem

Coleta dos resíduos registrando data e local de coleta com memória fotográfica

Descarregamento dos resíduos em local coberto por lona onde foram efetuados os procedimentos.

Coleta de quatro amostras de 100 quilos, sendo três de base e laterais e uma de topo, rompendo antes os sacos plásticos contendo os resíduos, homogeneizando toda a massa, antes da coleta de quatro amostras.

Pesagem de todo o resíduo coletado (quatro amostras ou todo o material como foi o caso, por ser este inferior a 1,5 toneladas, como foi procedido).

Disposição dos resíduos coletados sobre uma longa, sendo feito o procedimento da separação dos materiais, segundo suas características físicas, químicas e biológicas.

\section{Fonte: CEMPRE}

Os critérios de classificação utilizados quanto à tipificação - urbanos (domésticos, comerciais, industriais, hospitalares), industriais, aspectos sanitários, de periculosidade iminente e potencial e a degradabilidade (tempo 
de residência), são definidos de acordo com a legislação ambiental vigente e as normas ABNT - BR (Quadro 2).

Quadro 2: Características de alguns plásticos

\begin{tabular}{|c|c|c|}
\hline SIGLA & NOMENCLATURA & APLICAÇÕES \\
\hline $\mathrm{EVA} / \mathrm{PU}$ & $\begin{array}{l}\text { Poliacetato de etileno vinil e } \\
\text { Poliuretano }\end{array}$ & $\begin{array}{l}\text { Solados de calçados, piscinas, caixa d'água, } \\
\text { espumas. }\end{array}$ \\
\hline PP & Polipropileno & $\begin{array}{l}\text { Embalagens para massas, biscoitos, potes } \\
\text { de margarina. }\end{array}$ \\
\hline PEBD & Polietileno de baixa densidade & $\begin{array}{l}\text { Embalagens de alimentos, sacos, lonas } \\
\text { agrícolas, tubos. }\end{array}$ \\
\hline PEAD & Polietileno de alta densidade & $\begin{array}{l}\text { Embalagens de bebidas baldes, frascos de } \\
\text { supermercados, produtos de limpezas, } \\
\text { garrafas. }\end{array}$ \\
\hline PET & Politereftalato de etileno & Garrafas e copos descartáveis. \\
\hline OS & Poliestireno & $\begin{array}{l}\text { Aparelho de som e rádio, computadores, } \\
\text { copos descartáveis, potes. }\end{array}$ \\
\hline PVC & Policlorero de vinila & Tubos, garrafas e filmes a condicionadores. \\
\hline
\end{tabular}

\section{Fonte: CEMPRE}

No quadro 3, dispomos a classificação dos resíduos encontrados na borda da mata conforme o provável tempo de permanência, os grupos e as classes de enquadramento quanto à periculosidade físico-química e biológica respectivamente.

Quadro 3: Classificação dos resíduos sólidos

\begin{tabular}{|l|l|l|l|}
\hline RESÍDUO & PERMANÊNCIA & GRUPO & CLASSE \\
\hline Tipo & Degradabilidade & Periculosidade & Saúde \\
\hline Papel/papelão & De 3 a 6 meses & D1 & II \\
\hline Jornal & Até 6 meses & D1 & II \\
\hline Madeira & De 6 meses a 2 anos & D1 & II \\
\hline Madeira tratada & De 5 a 20 anos & D1 & II \\
\hline Toco de cigarro & Até 18 meses & D1 & II \\
\hline
\end{tabular}




\begin{tabular}{|l|l|l|l|}
\hline Tecidos comuns & De 6 meses a 2 anos & D1 & II \\
\hline Tecidos sintéticos & Até 5 anos & D1 & II \\
\hline Chicletes & Até 5 anos & D1 & II \\
\hline Fralda descartável/biodegradável & Até 1 ano & D1 & I \\
\hline Fralda descartável comum & Até 600 anos & D1 & I \\
\hline Recipientes plásticos & De 1 ano a 500 anos & D1 & II \\
\hline Filmes plásticos & De 1 a 50 anos & D1 & II \\
\hline Isopor & Até 10 anos & D1 & II \\
\hline Metais & De 10 a 500 anos & D1 & III \\
\hline Pneus & Indeterminado & D1 & II \\
\hline Garrafas de vidro & Indeterminado & D1 & III \\
\hline Baterias & Indeterminado & D1 & I \\
\hline Concreto & Indeterminado & D1 & III \\
\hline Porcelana/cerâmica & Indeterminado & D1 & III \\
\hline Restos vegetais & De 3 a 18 meses & D1 & II \\
\hline Remédios vencidos & Indeterminado & B1 & I \\
\hline
\end{tabular}

Fonte: CEMPRE

A degradabilidade dos resíduos sólidos e função das interações entre as características do ambiente (exposição ao ar e aos raios solares, a umidade, a temperatura, os ventos, o pH do meio, a atividade biológica, incluindo o homem e a declividade acentuada) com as propriedades físicas, químicas e biológicas e as diversas condições apresentadas pelos materiais assim como, estarem enterrados, empilhados. Dispersos, levando-se em conta ainda as propriedades e as reações entre as substancias constituintes dos descartes com os componentes naturais da mata.

Os resíduos encontrados procedem, na maioria das vezes, de fontes domiciliares e comerciais, tendo uma composição bastante diversificada, como por exemplo: restos de alimentos e embalagens, entulhos de construções, podas de árvores e jardins, fraldas descartáveis, rejeitos de oficinas, pilhas, oferendas religiosas, descartes de móveis e utensílios domésticos, etc. 


\section{RESULTADO E DISCUSSÃO}

Nas tabelas 1 e quadro 4, procuramos apresentar em uma matriz simplificada, a classificação dos atributos ambientais impactados nos meios físicos, biótico e antrópico.

Tabela 1: Matriz simplificada de síntese e classificação de impactos

\begin{tabular}{|l|l|l|l|l|l|l|l|l|l|l|l|}
\hline & \multicolumn{7}{|c|}{ CLASSIFICAÇÃO } \\
F DOS IMPACTOS \\
F
\end{tabular}




\begin{tabular}{|c|c|c|c|c|c|c|c|c|c|c|}
\hline $\begin{array}{l}\text { INTERESSES HUMANOS, ESTÉTICOS E } \\
\text { RECREATIVOS - região eminentemente } \\
\text { turística; } \\
\text { Significante atividade fabril e agropecuária. }\end{array}$ & $\mathrm{N}$ & $\begin{array}{l}D \\
D / 1\end{array}$ & $P$ & $\mathrm{R}$ & $\begin{array}{l}C \\
P\end{array}$ & $\mathrm{R}$ & I & $E$ & $A$ & $A$ \\
\hline
\end{tabular}

Fonte: CEMPRE

Quadro 4: Características dos impactos

\begin{tabular}{|c|c|c|c|}
\hline \multicolumn{2}{|c|}{ CRITÉRIOS ESTABELECIDOS } & \multirow{2}{*}{$\begin{array}{l}\text { CARACTERÍSTICAS } \\
\text { IMPACTOS } \\
\text { Positivo } \\
\text { Negativo }\end{array}$} & \multirow{2}{*}{$\begin{array}{l}\text { DOS } \\
\begin{array}{l}\mathrm{P} \\
\mathrm{N}\end{array}\end{array}$} \\
\hline 1 & Critério de valor ou qualidade & & \\
\hline 2 & Critério de ordem ou tipificação & $\begin{array}{l}\text { Direto } \\
\text { Indireto }\end{array}$ & $\begin{array}{l}D \\
\text { I }\end{array}$ \\
\hline 3 & Critério de interferência ou existência & $\begin{array}{l}\text { Novo } \\
\text { Presente }\end{array}$ & $\begin{array}{l}N \\
P\end{array}$ \\
\hline 4 & Critério espacial ou abrangência & $\begin{array}{l}\text { Local } \\
\text { Regional }\end{array}$ & $\begin{array}{l}\mathrm{L} \\
\mathrm{R}\end{array}$ \\
\hline 5 & Critério de duração ou periodicidade & $\begin{array}{l}\text { Cíclica } \\
\text { Temporária } \\
\text { Permanente }\end{array}$ & $\begin{array}{l}\mathrm{C} \\
\mathrm{T} \\
\mathrm{P}\end{array}$ \\
\hline 6 & Critério dinâmico ou plástico & $\begin{array}{l}\text { Reversível } \\
\text { Irreversível }\end{array}$ & $\begin{array}{l}\mathrm{R} \\
\mathrm{l}\end{array}$ \\
\hline 7 & Critério de temporalidade & $\begin{array}{l}\text { Imediato } \\
\text { Médio } \\
\text { Longo Prazo }\end{array}$ & $\begin{array}{l}\mathrm{I} \\
\mathrm{M} \\
\mathrm{L}\end{array}$ \\
\hline 8 & Critério probabilístico ou potencial & $\begin{array}{l}\text { Certo } \\
\text { Provável } \\
\text { Existente }\end{array}$ & $\begin{array}{l}C \\
P \\
E\end{array}$ \\
\hline 9 & $\begin{array}{l}\text { Magnitude } \\
\text { Grau de alteração de impacto sobre um } \\
\text { atributo ambiental afetado }\end{array}$ & $\begin{array}{l}\text { Alta } \\
\text { Média } \\
\text { Baixa }\end{array}$ & $\begin{array}{l}A \\
M \\
B\end{array}$ \\
\hline 10 & $\begin{array}{l}\text { Importância } \\
\text { Peso relativo ao atributo ambiental } \\
\text { afetado }\end{array}$ & $\begin{array}{l}\text { Alta } \\
\text { Média } \\
\text { Baixa }\end{array}$ & $\begin{array}{l}A \\
M \\
B\end{array}$ \\
\hline
\end{tabular}

Fonte: CEMPRE 
O quadro 5 explicita os atributos e os impactos reais e potenciais decorrentes da atividade, enquanto os quadros 6 e 7, demonstram a sequência lógica, correlacionando a atividade com os atributos ambientais afetados.

Quadro 5: Atributos ambientais impactados por resíduos sólidos

\begin{tabular}{|l|l|}
\hline ATRIBUTOS & IMPACTOS \\
\hline $\begin{array}{l}\text { Recursos } \\
\text { hídricos }\end{array}$ & $\begin{array}{l}\text { Produção de lixiviados e fenômenos de escorrimento, com } \\
\text { possibilidade de contaminação de aquíferos e águas } \\
\text { superficiais. }\end{array}$ \\
\hline Flora e Fauna & $\begin{array}{l}\text { Modificação e/ou interferência na cobertura vegetal. } \\
\text { Perigo de incêndios florestais. } \\
\text { Morte de animais atropelados ou intoxicados. }\end{array}$ \\
\hline Economia & $\begin{array}{l}\text { A imagem da empresa pode influir positividade ou ou do dor } \\
\text { negativamente em sua competitividade dentro do setor } \\
\text { produtivo ou prestação de serviços que cada vez exigem } \\
\text { uma qualidade dos processos operacionais. }\end{array}$ \\
\hline Paisagem & Degradação da paisagem. \\
\hline Solo & Indutor de erosão de solo com as suas consequências. \\
\hline
\end{tabular}

Fonte: CEMPRE

Quadro 6: Impactos negativos

\begin{tabular}{|c|c|c|c|}
\hline Atividade(1) & Aspectos(2) & Agentes(3) & $\begin{array}{l}\text { Atributos ambientais } \\
\text { impactados (5) }\end{array}$ \\
\hline $\begin{array}{l}\text { Operacionaliz } \\
\text { ação da } \\
\text { rodovia }\end{array}$ & $\begin{array}{l}\text { Geração e } \\
\text { acúmulo de } \\
\text { resíduos no } \\
\text { interior da } \\
\text { borda florestal } \\
\\
\\
\text { Direito Real }\end{array}$ & $\begin{array}{l}\text { Resíduos diversos } \\
\text { descarados por usuários } \\
\text { da via, entulhos } \\
\text { provenientes de obras de } \\
\text { manutenção(bota-fora), } \\
\text { aparatos de proteção e } \\
\text { sinalização e partes de } \\
\text { veículos acidentados }\end{array}$ & $\begin{array}{l}\text { Economia } \\
\text { Paisagem } \\
\text { Fauna e Flora } \\
\text { Águas superficiais } \\
\text { subterrâneas } \\
\text { Solo } \\
\text { Bem estar social }\end{array}$ \\
\hline
\end{tabular}

Fonte: CEMPRE 
Quadro 7: Impactos positivos

\begin{tabular}{|l|l|l|l|}
\hline Atividade & Aspectos & Agente & $\begin{array}{l}\text { Atributos } \\
\text { ambientais } \\
\text { afetados }\end{array}$ \\
\hline $\begin{array}{l}\text { Operacionalizaçã } \\
\text { o da rodovia }\end{array}$ & $\begin{array}{l}\text { Desenvolvimento } \\
\text { socioeconômico e } \\
\text { cultural. }\end{array}$ & $\begin{array}{l}\text { Circulação } \\
\text { pessoas } \\
\text { mercadorias }\end{array}$ & e \\
& Direto e Real & $\begin{array}{l}\text { Emprego } \\
\text { Economia } \\
\text { Bem estar social } \\
\text { Turismo } \\
\text { Infraestrutura supra } \\
\text { regional de } \\
\text { transporte }\end{array}$ \\
\hline
\end{tabular}

Fonte: CEMPRE

Obs. O aspecto é direto se o impacto for caracterizado como falha operacional da rodovia quanto à gestão dos resíduos sólidos, e indireto se assim não o for.

Citamos como exemplo de aspecto direto, os entulhos resultantes da manutenção e conservação da rodovia e ferragens de desastres sendo lançados no interior da mata, já como exemplo de aspecto indireto os danos provocados por usuários da rodovia.

O aspecto é potencial (contingencial) devido existência da rodovia per si e pela possibilidade iminente (alta probabilidade) de acidentes e descartes de resíduos pelos usuários.

- $\quad$ Atividade (1) - realização de uma função especifica de trabalho, no caso empresarial.

- $\quad$ Aspecto (2) expressa detalhes qualitativos ou quantitativos internos de uma determinada ação, processo ou estado que interage com o todo, direta ou indiretamente, positiva ou negativamente.

- Aspecto direto -Faz-se sentir diretamente, sem intermediários, espera-se que aconteça.

- $\quad$ Aspecto indireto - Necessita de terceiros para a consubstanciação.

- $\quad$ Aspecto real - Premissa verdadeira, o que existe de fato, é de se esperar. 
- Aspecto potencial - Poder ou força potencial, virtual, possível, contingencial.

- $\quad$ Agente (3) - pessoa ou algo que induza, produza ou desencadeie ações ou efeitos no todo.

- Impacto (4) - ato ou o resultado de impactar, impressão ou efeitos muito fortes consequentes de certas ações, omissões ou acontecimentos que possam alterar o todo, positiva ou negativamente.

- $\quad$ Atributo(5) - aspectos peculiares, qualitativos ou quantitativos, que distingue um integrante de um conjunto ou sistema observado.

Quanto aos resultados analíticos das amostras temos:

1. Quanto à origem podem ser considerados urbanos (comerciais e domiciliares).

2. Quanto a degradabilidade, $2 / 3$ do material apresenta difícil degradabilidade com alto grau de permanência se porventura venham a ser carreados ou lançados para o interior da borda florestal. Do total de resíduos inertes 29, 3\% p/p, a maior contribuição provém de louças, cerâmicas e metais.

- fração matéria orgânica, $2.45 \mathrm{Kg}(3,5 \%$ p/p são provenientes de oferendas em cultos religiosos e fraldas descartáveis, sendo o restante oriundo de sacolas contendo lixo doméstico e descarte de sabugos de milho e fruto coco - Cocos nucifera, que uma vez consumido os grãos e seu liquido respectivamente, são descartados ao longo da rodovia.

- a maior concentração percentual desta amostra é de resíduos plásticos e inertes, com um total de $23,3 \mathrm{Kg}$ e $20,5 \mathrm{Kg}$, correspondendo a 33, $3 \%$ p/p e $29,3 \%$ p/p respectivamente do total da amostra. Os resíduos plásticos de maior contribuição são as embalagens de alimentos em geral.

3. Quanto à periculosidade físico- química é importante ressaltar a propriedade de combustibilidade dos resíduos Classe II com relação à floresta, visto que estes compõem dois terços da amostra-\% p/p e englobam as frações papel plásticos, madeira, pneus e trapos.

- $\quad$ baterias e pilhas foram consideradas a parte. 
Obs: O volume de resíduos recolhidos em dias normais é $50 \%$ menor do que o que foi coletado e analisado na amostra 1 (Semana Santa), apresentando, porém, gravimetria semelhante.

Face às constatações descritas no trabalho, podemos afirmar que o fator incisivo, e causa da lide, foi o acúmulo de resíduos no interior da borda florestal, constituindo estes o passivo ambiental legado à empresa por época da concessão e acrescido durante a gestão da concessionária.

Na verdade, 90,0 \% dos danos são decorrentes do acúmulo de resíduos sólidos e está ocorrendo nas áreas lindeiras (quinze metros a contar das margens da Rodovia), onde a maior parte dos resíduos descartados acomodamse junto à vegetação.

Os resíduos sólidos descartados na via e acumulados na área do Parque, além do impacto negativo sob o ponto de vista estético-paisagístico, podem agravar a situação de risco natural existente devido ao acúmulo dos mesmos, impedindo o livre escoamento das águas pluviais (drenagem), podendo conduzir o solo a processos erosivos, a deslizamentos com consequências maiores.

Além disso, dependendo da quantidade e qualidade do resíduo é possível a contaminação dos solos e dos corpos hídricos como, por exemplo, pelo resíduo hospitalar, as oferendas religiosas, carcaças de animais, provavelmente atropelados, e lixo doméstico coletados em sacolas contendo fraldas descartáveis e restos de alimentos.

Em todas as amostras, foi observada a presença do resíduo vidro, principalmente de bebidas diversas, latas de bebidas e metais resíduos inertes Classe III não pontuais, descartados ao longo da rodovia aleatoriamente.

Com relação ao resíduo plástico "PET", este foi considerado separadamente devido ser o material mais utilizado para o acondicionamento de bebidas refrigerantes, e encontrados em grande quantidade em toda a extensão da pista e interior da floresta.

Observou-se grande quantidade de $\operatorname{cocos}$ e sabugo de milho verde, coletados no km 89,6 e imediações, devido ao consumo e descarte na pista e/ou nas bordas florestais.

Foi coletada também, uma considerável quantidade de pilhas e baterias (de celulares e aparelhos eletrodomésticos) em todas as amostras - 15,1 Kg de 
resíduo Classe I sendo estes considerados a parte por sua periculosidade e destinados a uma caixa de coleta.

Sendo uma rodovia de escoamento de produção hortifrutícola, foram identificados vários pontos de descarte de matéria orgânica e embalagens, certamente provenientes dos veículos transportadores de tais produtos.

Os estabelecimentos que comercializam alimentos e que se localizam na extensão total da Rodovia podem contribuir direta e/ou indiretamente para o lançamento e acúmulo de resíduos sólidos na rodovia e na área do parque, visto que é notória e relevante quantidade de resíduos classificados como resíduos jovens, por não apresentarem sinais de deterioração como, por exemplo: plásticos diversos utilizados como embalagem de biscoitos, chocolates, balas, doces, pães, garrafas de água mineral, sucos, refrigerantes, copos descartáveis e sacolas plásticas.

70,0\% dos resíduos coletados na área do parque são classificados como senis latas, pneus, vidro, cerâmica, louça, carcaça de veículos, plásticos e outros que são de difícil degradabilidade e, por apresentarem sinais evidentes de longa permanência na mata.

20\% são maduros, com a mesma composição já descrita, porém, devido ao aspecto e características, tem uma permanência estimada em torno de dois anos, apresentando ainda como constituintes, madeira, pano, trapo e restos orgânicos (coco e sabugos de milho).

10,0\% dos resíduos, apesar de apresentarem as características de material de difícil degradabilidade, devido ao exame de sua aparência, foram classificados como lixo jovem, e possivelmente foram lançados a menos de um ano na a do parque como, por exemplo, pneus, garrafas de "PET", peças automotivas, etc.

No presente, temos notícias da interdição da Estrada do Colono com extensão de 18 quilômetros cortando o Parque Nacional do Iguaçu (RS). Apesar do embargo à mesma ainda está sendo depredada por vândalos apesar de já estar sendo providenciada a recuperação do ambiente alterado, pois se constatou que os benefícios proporcionados não justificavam os prejuízos causados pelo seu uso. 


\section{CONCLUSÃO}

Os benefícios das rodovias geralmente são significativos e quase que exclusivamente socioeconômicos. Os impactos negativos se fazem sobre todo o ambiente, tanto físico, como biótico ou antrópico. Há impactos positivos também sobre os meios físico e biótico, mas geralmente são poucos e indiretos, pois as rodovias criam modificações profundas no ambiente e representam uma barreira permanente para os processos de evolução natural, além de serem veículo de grande poluição em todas as suas fases.

Os métodos de monitoramento da rodovia e a sua manutenção de forma permanente e eficiente, assim como obras para redução de seus impactos são imprescindíveis e devem se adequar ao plano de manejo do parque. $O$ monitoramento e controle devem levar em conta todos os aspectos envolvidos para se avaliar não só a qualidade ambiental da rodovia, mas também sua extensão ao desenvolvimento sustentável em toda sua plenitude.

\section{REFERÊNCIAS BIBLIOGRÁFICAS}

ALMEIDA, J. R. et al. Perícia Ambiental. Editora Thex. Rio de Janeiro 2000.

ALMEIDA, J. R. Gestão Ambiental. Editora Thex. Rio de Janeiro 2000.

ALMEIDA, S. M. Aprimoramento do procedimento de licenciamento ambiental prévio em rodovias. Dissertação de Mestrado. PET/COPPE/UFRJ. 2012.

BELLIA, V.; BIDONE, E. D. Rodovias, Recursos Naturais e Meio Ambiente, EDUFF / DNER, Rio de Janeiro 1993.

BELLIA, V. Introdução a Economia do Meio Ambiente. IBAMA. Brasília 1996.

BIDONE, F. R. A. et al, conceitos Básicos de Resíduos sólidos. Escola de Engenharia de São Carlos USP, São Paulo 1999.

CUNHA, A. L. Impactos ambientais em florestas tropicais - Estrada Parque: uma solução ecológica. PET/COPPE/UFRJ. 2015

CUNHA, S. B.; GUERRA, A. T. Avaliação e Perícia Ambiental, Bertrand Brasil, Rio de Janeiro 2000.

CARVALHO, C. G. Legislação Ambiental Brasileira. Leis, Decretos. Resoluções, Portarias e Jurisprudência. Editora Millennium, Rio de Janeiro 2000.

DERMAJOROVIC, J. Revista de administração de empresas - Sciello Brasil. 1995. 
FARIA, S. C. Análise de Riscos Ecológico -um método para o planejamento em bases ecológicas. UNB/CIORD, Brasília 1996.

JACOBI et al. Estudos avançados (25) - Gestão de resíduos sólidos em São Paulo: desafios da sustentabilidade. 2011.

MONTEIRO, J. H. P. et al. Manual de Gerenciamento Integrado de Resíduos sólidos, IBAN / SEDU-PR. Brasília 2000.

MOURA, L. A. A. Qualidade e Gestão Ambiental. Editora Juarez de Oliveira. São Paulo 2000.

MOTTA, R. S. Manual para Avaliação Econômica de Recursos Ambientais (CEMA / IPEA - COBIO/MMA), Brasília 1998.

NOHARA, J. J. et al. GS40 Resíduos Sólidos: Passivo Ambiental e Reciclagem de Pneus. 2006.

OLIVEIRA, R. M, et al. Resíduos Sólidos, Ambiente e Saúde -Uma Visão Multidisciplinar, Editora Fiocruz, Rio de Janeiro 2000.

OTERO, M. L. et al. Lixo Municipal - Manual de Gerenciamento Integrado. IPT/CEMPRE, São Paulo. 1999.

PINTO, L. E. M. et al. I Congresso Brasileiro de Gestão Ambiental. 2010.

PORTILHO. F. et al. Curso de Capacitação em Planejamento e Gestão de Resíduos Sólidos. Proenco / NUSEG-UERJ, Rio de Janeiro 1999.

PROJETO BR-0295 - Relatório de avaliação ambiental do programa de avaliação de rodovias; DER / BID, Secretaria de Transportes SP. São Paulo ABRIL/2001.

SILVA, E. R. Análise do crescimento da motorização no Brasil e seus impactos na mobilidade urbana. Dissertação de Mestrado. Rio de Janeiro. PET/COPPE/UFRJ. 2011.

SILVA, E. Técnicas de Avaliação de Impactos Ambientais. CP, Viçosa 1999.

SOUZA, C. P. Execução dos Programas de Monitoramento Ambiental da Via Lagos. 2007.

TOMMASI, Luiz Roberto. Estudo de Impacto Ambiental. CETESB, São Paulo 1993.

VALENÇA, M. Z. Os Caminhos da Gestão Compartilhada. CEMPRE Informa - n. 41. Set / out 1989.

WANDERLEY, M. Análise Gravimétrica do Lixo da Cidade do Rio de Janeiro. Série Histórica. Diretoria Técnica e Industrial, Gerência de Pesquisas Aplicadas. Comlurb. Rio de Janeiro. 2000. 